\title{
Ecoturismo e conservação ambiental: contextualizações gerais e reflexões sobre a prática ${ }^{1}$
}

\author{
Gabriela Barros Rodrigues, Ozelito Possidônio de Amarante-Junior
}

\begin{abstract}
RESUMO
O presente trabalho apresenta uma breve análise bibliográfica que busca em alguns textos científicos alicerces para discutir o tema e, sobretudo, ressalta observações relacionadas a vivências de campo que relacionem o Ecoturismo e a conservação dos recursos naturais, sob a perspectiva do formato em que as práticas estão sendo desenvolvidas. Neste estudo, são apresentados algumas vivências e exemplos relacionados a localidades que têm a atividade do turismo em fase de implantação ou já consolidada. O texto ainda fomenta a discussão a respeito do uso do termo Ecoturismo e os equívocos cometidos em sua comercialização e como tal realidade vêm trazendo impactos negativos aos ambientes onde a atividade turística pode se apresentar como uma alternativa de desenvolvimento local.
\end{abstract}

PALAVRAS- CHAVE: Ecoturismo, Turismo de Aventura, Planejamento Comunitário, Biodiversidade.

\section{Ecotourism and conservation: general context and reflections on practice}

\section{ABSTRACT}

This paper presents a brief literature review which seeks in some scientific texts foundation for discussing the subject and, above all, emphasizes comments related to experiences that relate the field of Ecotourism and conservation of natural resources, from the perspective of the format in which practices are being developed. In this study, we present some examples and experiences related to locations that have the activity of tourism under implementation or already consolidated. The text also encourages discussion on the use of the term ecotourism and mistakes committed in their marketing and as such really brings negative impacts to the environment where tourism can be presented as an alternative development site.

KEY-WORDS: Ecotourism, Adventure Tourism, Community Planning, Biodiversity 


\section{Introdução}

Uma das explicações para a origem da atividade turística está intimamente ligada às necessidades humanas. Deslocamentos geográficos se deram em função da sobrevivência humana e evoluíram, contribuindo para a consolidação do formato de turismo atual. O campo de estudo da Biogeografia através de suas áreas de conhecimento podem subsidiar a afirmação em suas considerações que agregam deslocamento e conservação da espécie humana, ao longo da trajetória histórica da humanidade. Brown e Lomolino (2006:573) questionam se "nossa espécie exibe padrões de dispersão e modificação similares àqueles que ocorrem na maioria do planeta?"

As manifestações de peregrinação às terras santas ou a esperada visita de Zeus nos jogos olímpicos na Grécia Antiga também se dão através das viagens. Assim, considerações históricas a respeito da criação dos primeiros equipamentos de hospedagem; dos caminhos, das ferrovias e estradas rodoviárias; do aumento exponencial do número de viagens e de turistas no pós-guerra; da alienação no ócio e no lazer na sociedade pós-moderna, fazem-se fundamental para discutir a atividade turística (REJOWSKI, 2002). Como ressalta Sancho (2001:3).

Nos anos 50 a viagem internacional foi se tornando cada vez mais acessível a uma parcela maior da população devido a diferentes fatores, como o aparecimento do avião a jato para passageiros como resposta ao término da Segunda Guerra, o baixo preço do petróleo, a maior renda disponível das famílias, o aparecimento das férias remuneradas e o aumento do tempo livre disponível às populações dos países industrializados. O desenvolvimento das comunicações e dos meios de transporte foram fatores determinantes.

Esses itens são aspectos relevantes ao retratar quais questões sustentam historicamente a trajetória e a implantação da atividade turística nas sociedades atuais. A Figura 1, por exemplo, ilustra com a força da imagem a busca contemporânea por atividades turísticas, em um dos destinos naturais mais procurados do Brasil na atualidade, Circuito Turístico Serra do Cipó/MG.

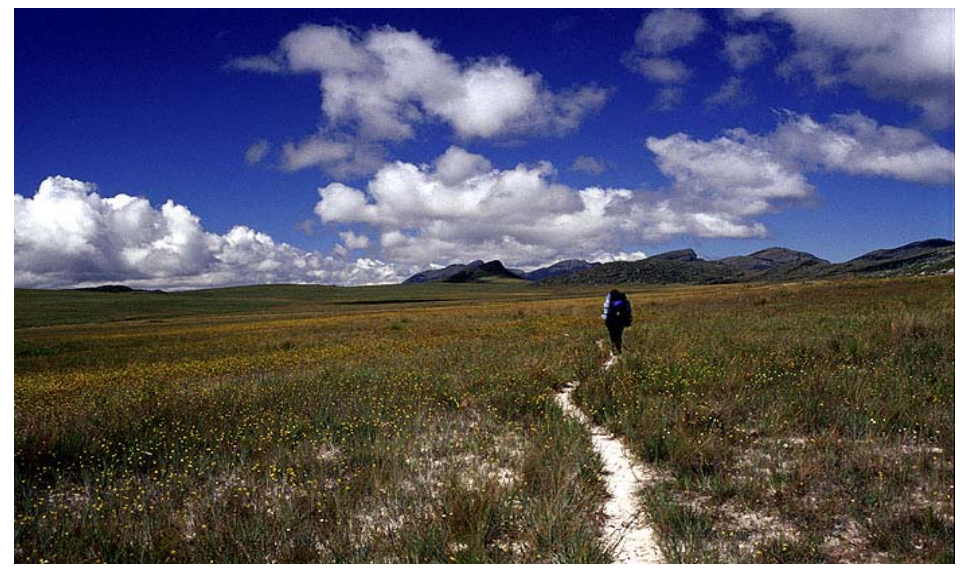

Figura 1: Caminhada Soberbo, Lapinha, Circuito Turístico Serra do Cipó, MG. Foto: Gustavo Baxter. 
O crescimento desta atividade, que está alicerçado em fatores antropológico, histórico, econômico, social, geográfico, ecológico e cultural, "é um fenômeno social que consiste no deslocamento voluntário e temporário de indivíduos ou grupo de pessoas" (CORIOLANO, 2003a:119). Portanto, ao se referir à atividade turística, o pesquisador deverá entender que as necessidades humanas aumentaram muito. E também que as exigências multidisciplinares da atividade proporcionalmente aumentaram a necessidade de competências, no que condiz ao planejamento do turismo.

A busca do homem por entretenimento e lazer, diante do estresse da vida moderna, faz com que os moradores dos centros urbanos saturados procurem o ambiente natural e rural para turismo de lazer. Tal atividade de deslocamento como coloca Urry (1996:15) "são consumidas porque geram supostamente experiências prazerosas, diferentes daquelas com que nos deparamos na vida cotidiana".

É importante considerar quais são estas motivações que levam um determinado tipo de público a procurar um determinado conjunto de serviços. Existem várias razões que motivam as pessoas (demanda turística), a estarem nos mais diversos locais (oferta turística), distintos de sua casa.

A demanda turística é formada por turistas, viajantes e visitantes, e os levantamentos dos atrativos e conjunto de serviços da localidade em estudo; já a oferta turística é o conjunto de produtos turísticos postos a disposição do usuário turístico num determinado destino, para seu desfrute e consumo (SANCHO, 2001). A junção e análise das citadas variáveis podem originar componentes fundamentais em um processo de planejamento de turismo.

As questões referentes à conservação e uso da biodiversidade, desenvolvimento humano e lucro justo, podem estar pautadas no cruzamento dessas variáveis. Porém, ao planejar o turismo é preciso considerar o mesmo como uma atividade econômica e social.

É diante das observações de alguns casos de gestão e planejamento de Ecoturismo no Brasil, que o esse trabalho vem contribuir para a aproximação das bases teóricas e desejáveis diante dos modelos práticos reais. As vivências, observações e conclusões, se dão ao longo de alguns anos de visitação a determinados locais.

Como método, é feito um breve levantamento das referências bibliográficas de turismo e Ecoturismo no Brasil, comparando suas bases conceituais com observações referentes às dinâmicas de funcionamento e realização da atividade em algumas localidades turísticas.

A importância de fazerem-se considerações que integrem as bases teóricas da atividade segmentada do Ecoturismo e o formato de como os cenários vem sendo vendidos, faz-se de fundamental importância para o desenvolvimento de locais e de comunidades. De fato, a realidade das atividades ecoturísticas encontra-se (em muitos casos) distantes do sugerido pela literatura e legislação em termos de conceituação e gestão de impactos em regiões com tal uso.

As premissas, diretrizes e bases conceituais da atividade precisam ser aproximadas e lidas de forma cruzada com a realidade, a fim de diminuir o hiato estabelecido entre o ideal colocado pelas produções científicas e o que realmente vem sendo 
"estabelecido" pelo o mercado.

O que se percebe é uma confusão no que relaciona as atividades de visitação com os componentes de paisagens, como as bases sociais, históricas, antropológicas, naturais e econômicas de determinados lugares. $E$ ainda, que a partir de tais práticas de mercado, tal dinâmica vem sedimentando e solidificando impactos negativos e efetivos no cotidiano de comunidades e de ambientes distintos. Entendemos que, nessa dinâmica, "ciclos viciosos" são gerados, e o retrocesso dos efeitos na escala humana são detectados, bem como a rápida mutação dos locais ecoturísticos.

Para Coriolano (2003b:14), "(...) um dos maiores desafios da sociedade atual é promover o desenvolvimento centrado no homem". E para que o desenvolvimento de cenários e a conservação de componentes de paisagens ocorram, territórios precisam ser conservados em suas diversas essências, inclusive através do Ecoturismo.

\title{
Impactos do turismo
}

O turismo atualmente é considerado uma atividade econômica de grande importância, gerando um retorno financeiro da ordem de bilhões de dólares anuais em escala mundial (segundo a Organização Mundial do Turismo). E também tem a capacidade de movimentar vários segmentos e afetar relações sociais nos cenários intraregionais. Embora o turismo seja responsável pela produção de divisas internas e externas nos locais onde ele acontece, podem ser verificadas mudanças no contexto social das comunidades residentes, como também nas paisagens dos locais turísticos, o que pode gerar vários tipos de conflitos, ameaças culturais e impactos sob o território e a biodiversidade.

\begin{abstract}
Desenvolvimento, turismo e meio ambiente encontram-se em uma relação recíproca: atividades econômicas transformam o meio ambiente e o ambiente alterado constitui restrição externa para o desenvolvimento econômico e social. Contudo essa relação pode ser feita de forma controlada, mitigando impactos e agressões (CORIOLANO, 2003b:19) .
\end{abstract}

As mudanças sociais, portanto, podem ocorrer e serem compreendidas de forma positiva enquanto entendidas como geradoras e incentivadoras da conservação ambiental e da identidade patrimonial do local. E serão, por outro lado, negativas se forem verificados conflitos irresolúveis entre os residentes e os turistas e entre residentes e seu patrimônio. Isso vem sendo vivenciado por comunidades tradicionais, como, por exemplo, na Comunidade Quilombola do Açude (Figura 2). 


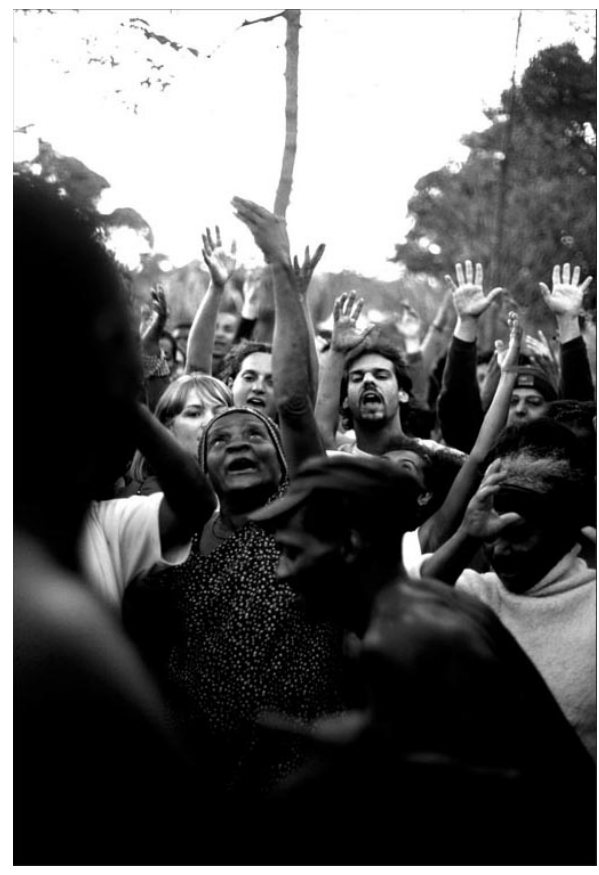

Figura 2: Comunidade Quilombola do Açude "Zona de amortecimento" do Parque Nacional da Serra do Cipó, MG. Foto: Gustavo Baxter.

O turismo pode ser uma atividade impulsionadora do desenvolvimento local nos lugares onde ele tem condições de ser implantado. Porém, a comunidade residente necessita entender como o mesmo funciona, quais são os seus pontos fortes e fracos, suas ameaças, oportunidades e tendências. Ou seja, apenas quando os residentes forem envolvidos num trabalho permanente de planejamento endógeno para interpretação e conservação cultural e ambiental, como cita o autor, que o mesmo alcançará mínimos impactos e poderá promover o desenvolvimento.

O desenvolvimento só se dá quando todas as pessoas são beneficiadas, quando atinge a escala humana e o turismo tanto pode se vincular ao crescimento econômico concentrado, como ao desenvolvimento social, o chamado desenvolvimento local (CORIOLANO, 2003b:13).

A ênfase no crescimento qualitativo da atividade turística possibilita a geração de uma atividade que seja pensada, sentida e articulada socialmente de forma responsável através da inclusão, do incentivo de residentes em atividades de cunho informativo, valorizador e conservacionista tanto do patrimônio cultural, social, humano e ambiental.

O processo de envolvimento da comunidade é indispensável para o fomento da sustentabilidade do Turismo Comunitário. Tal prática pode vir de forma gradual contribuir para o desenvolvimento de localidades no qual o turismo vem sendo planejado e 
implantado, gerando assim pequenos impactos no que se refere ao patrimônio do lugar. A Figura 3 ilustra o que seriam essas particularidades locais, ao retratar o cotidiano do saber e o fazer da pesca no litoral do país.

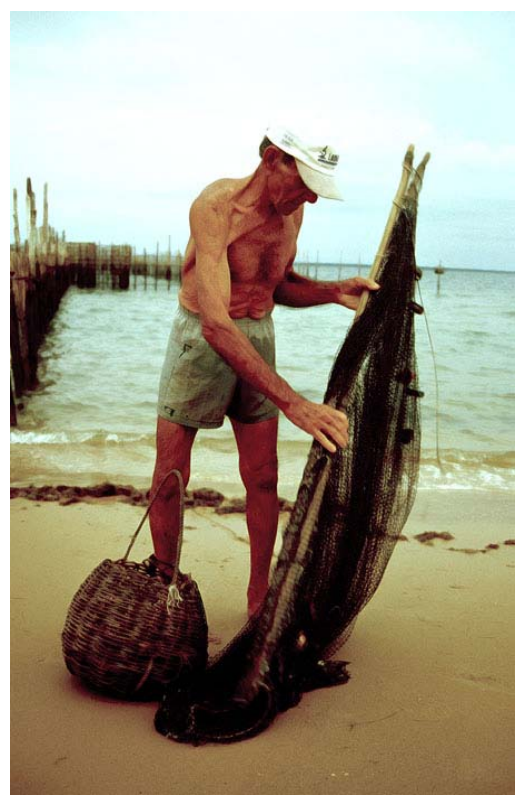

Figura 3: Comunidade de Pescadores - Barra Grande, BA. Foto: Gustavo Baxter.

O desenvolvimento local é aquele realizado em pequenos lugares de forma participativa, levando a mudanças socioestruturais, com caráter endógeno. Nele, os habitantes possuem relativa autonomia para explorar o potencial do território que beneficie a maioria deles e decidir como cada um pode contribuir com inovações. São os residentes os agentes principais do desenrolar de todo o processo de e zelam pela qualidade dos relacionamentos interpessoais, interinstitucionais, aproveitam as sinergias em benefício da coletividade ( CORIOLANO; LIMA, 2008:393).

A sustentabilidade no desenvolvimento do processo turístico pode acontecer, portanto, se a gestão local do turismo releva estes fatos. Caso contrário pode ocorrer um processo de invasão cultural, através da exploração e comercialização maciça de produtos de consumo de massa, que banalizam e contradizem a sustentabilidade (cultural, social e ambiental), ameaçando o possível uso de recursos turísticos pelas gerações futuras.

É relevante fomentar, destacar e refletir sobre qual tipo de desenvolvimento se refere, quando se pensa nos moldes do turismo, nas limitações das capacidades de suporte de atrativos, nas bases cotidianas de comunidades específicas. E sobretudo, para quem se dirige tais ações e em qual período de tempo, pensa-se em conservação de paisagens e de lugares.

No atual cenário de turismo mundial, é a pratica do Ecoturismo que mais ganha 
adeptos a todo o momento. A prática da atividade de visitação, em locais divulgados como "paisagens naturais inesquecíveis", gira atualmente e na realidade, (infelizmente), como um rótulo, que vende produtos na prateleira de supermercados. Segundo Morais e Saraiva-Filho (2008:260)

A reboque de abundantes estudos acadêmicos sobre o tema e o forte crescimento desse mercado, surge o turismo de aventura, confundido e muitas vezes considerado como sucedâneo de ecoturismo, devido a proximidade conceitual e do espaço (natural) onde ambos são comumente operados e praticados...

Das relações propostas pelo o Ecoturismo com os componentes de paisagens onde o mesmo está sendo realizado, em contraponto, ao formato da comercialização de qualquer atividade que use como cenário a natureza, que surge uma confusão conceitual e prática.

...há muitas formas de turismo na natureza: de sol e praia, de aventura,rural entre outro. Contudo cada segmento é realizado em ambientes especiais, com focos diferenciados, tendo como ponto em comum o contato com a natureza. No ecoturismo a contemplação da paisagem, a interação com as comunidades locais têm foco especial ( CORIOLANO;LIMA, 2008:338).

O que se pode perceber é que a terminologia Ecoturismo é comercializável. E que sua natureza conservacionista da atividade vem sofrendo equívocos diante dos procedimentos do mercado. Pois, existe um confronto entre as diretrizes para a conservação e as projeções de rendimentos financeiros dos realizadores, não atendendo aos limites sócios naturais dos locais.

Como em períodos contemporâneos a tomada da consciência ambiental vem sendo discutida e resgatada, existem vários consumidores do turismo que querem optar pela realização de atividades em cenários naturais. Porém, não cabe aos mesmos discutir com seu operador se a sua conduta de realização de atividades, condiz com os limites daquele atrativo. O mesmo (consumidor) pode pressupor que ao comprar uma atividade de caminhada entre outras, todos os protocolos de conservação ambiental estavam sendo contemplados, e mesmo, que não existe diferenciação entre Ecoturismo e Turismo de Aventura e natureza.

Tal fato alimenta essa confusão conceitual e prática, que vem contribuindo para a não conservação dos atrativos diferenciais do segmento, que são as comunidades locais e a biodiversidade. Porque se vende e se compra Ecoturismo, ainda de forma pouco esclarecida sobre as reais bases que o referenciam. E ainda, os próprios operadores e profissionais de mercado tratam as práticas de aventura e natureza como uma atividade ecoturística.

Ao se analisar as circunstâncias que confrontam capacidades de suporte de atrativos com a projeção de lucros relacionados à prestação de serviços, é que se ressalta um vício na atividade. E ainda, como fator contribuinte, realiza-se a atividade 
contando somente com os aspectos naturais locais, não estabelecendo uma ligação com as comunidades residentes e suas questões sociais.

A Figura 4 ilustra uma exceção dentro do Turismo de Aventura. Aqui, a atividade realizada tem uma formatação interessante, pois o turismo é utilizado como uma ferramenta para a formação empresarial, respeitando as capacidades de suporte do lugar, e envolvendo atores locais no processo.

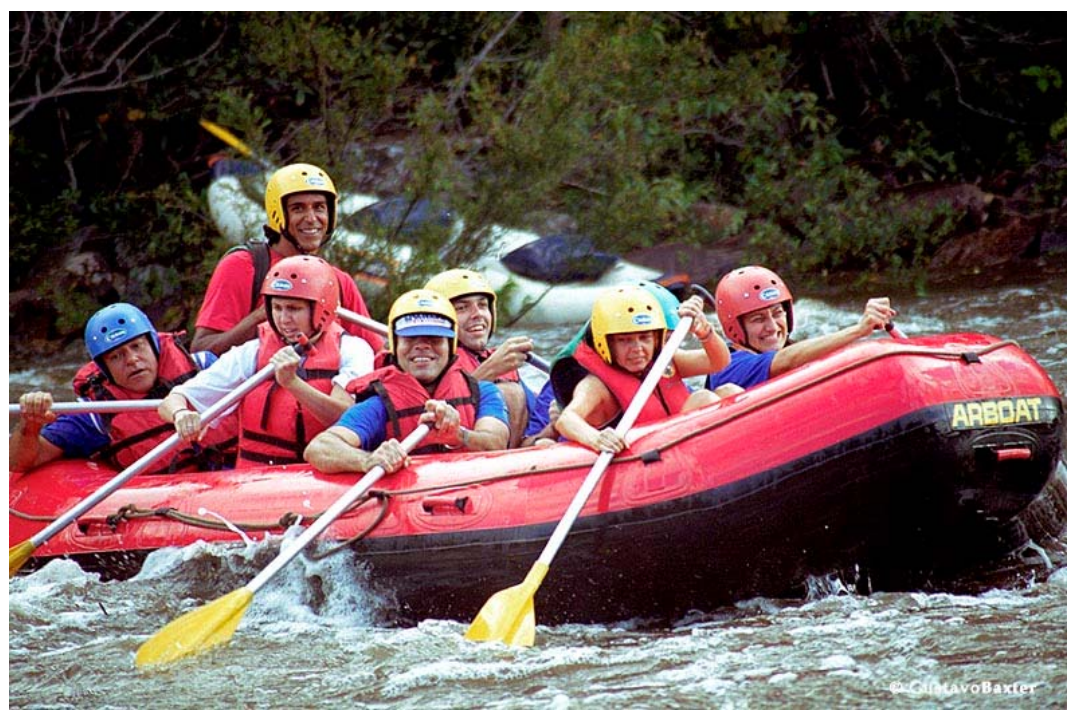

Figura 4: Prática de Rafting, Rio Cipó. APA Morro da Pedreira. Serra do Cipó, MG. "Programa Treinar". Foto: Gustavo Baxter.

Então, ao relevar e analisar a prática do Ecoturismo a partir do que já foi citado pode-se questionar sobre qual o tipo de Ecoturismo está sendo praticado na atualidade? A prática de Ecoturismo, turismo ecológico e turismo de aventura e natureza são as mesmas atividades? As práticas de aventura e natureza são vendidas como Ecoturismo? Como os gestores das Unidades de Conservação e a legislação ambiental nacional, relacionam-se com os empreendedores e prestadores de serviços turísticos para a realização de uma melhor prática? Se forem, como são feitos os levantamentos, pesquisas e monitoramento de atrativos?

Diante das questões colocadas, a necessidade de resgatar alguns conceitos sobre o Ecoturismo se faz importante, porque possibilita uma análise comparativa do que é proposto em termos de referências e teoria e a prática, no cenário atual. "O $E$ coturismo é mais do que uma elite de amantes da natureza. É, na verdade, um amálgama de interesses que emergem de preocupações de ordem ambiental, econômica social" (WESTERN, 2002:13).

Ecoturismo, segundo a definição dada pela Ecotourism Society, é "a viagem responsável a áreas naturais, visando a preservar o meio ambiente e a promover o bem estar da população local".

E, ainda, segundo o Grupo de Trabalho Interministerial em Ecoturismo (1994) 
Ecoturismo é um segmento da atividade turística que utiliza, de forma sustentável, o patrimônio natural e cultural, incentiva a sua conservação e busca a formação de consciência ambientalista através da interpretação do ambiente, promovendo o bem estar das populações envolvidas.

O Ecoturismo, ao ser planejado, salienta questões referentes à ecologia, à estética, à economia e ao aspecto social. Seu desenvolvimento, como ferramenta para o desenvolvimento local, fundamenta-se em uma sistemática interpretação do espaço sociocultural.

O Ecoturismo está deixando de definir-se como turismo de natureza de pequena escala para estabelecer-se como um conjunto de princípios aplicáveis a qualquer tipo de turismo que se relacione com a natureza (WESTERN, 2002:13).

Assim, o Ecoturismo apresenta tendências interessantes em relação à atividade turística planejada e responsável, pois identifica a essência de cenários naturais incorporando-as à prática, mesmo quando essa atividade é mais próxima do turismo de aventura, como ilustra a Figura 5.

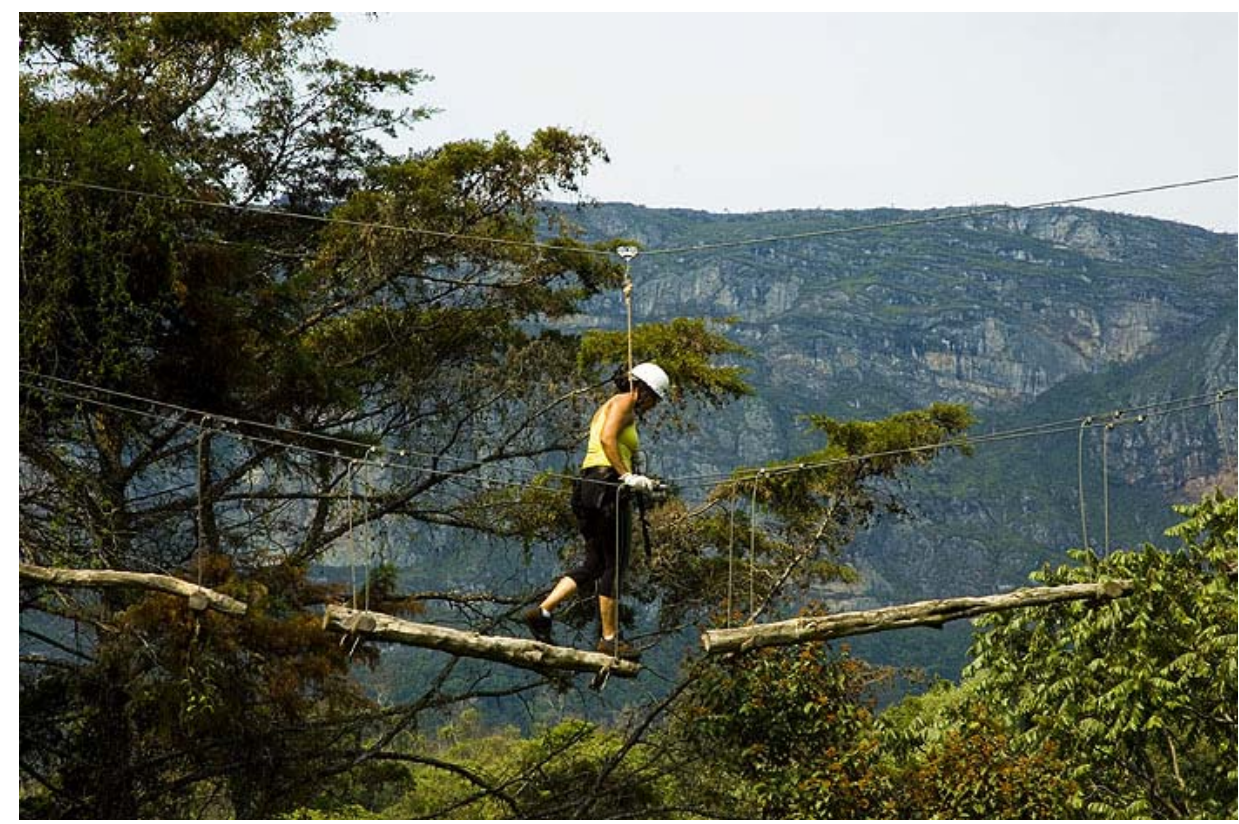

Figura 5: Prática de Arvorismo tendo o cenário natural como elemento constituinte. Centro de Aventura Canela de Ema, Caeté, MG. "Programa Treinar". Foto: Gustavo Baxter.

E mais ainda, o Ecoturismo tende a valorar e envolver a comunidade local em sua prática, já que os mesmos são conhecedores de seu lugar e podem promover a sua conservação, podendo incrementar a renda de suas famílias, como também gerar novos postos de empregos. 
A prestação simples de atendimento por si só é um diferencial e pode ser composto pelo característico jeito de falar do nativo até o preparo de comida caseira, feita com ingredientes colhidos na horta local. A observação da revoada de pássaros ou da espécie endêmica florística no alto da serra, acompanhada por guias locais, também podem ser citadas como alguns exemplos de envolvimento comunitário.

No Parque Nacional da Serra do Cipó, situado a 100 km de Belo Horizonte MG, um dos atrativos mais bonitos e importantes em termos de concentração de espécies e fragilidade ecossistêmica, denominado de Poço Azul, está e permanecerá interditado. Tal medida foi tomada para restaurar a queda d'água e minimizar impactos ocasionados pela visitação turística, atraída por uma divulgação maciça do atrativo, gerando um ciclo desgastante de mau uso. A Figura 6 ilustra um desses impactos negativos.

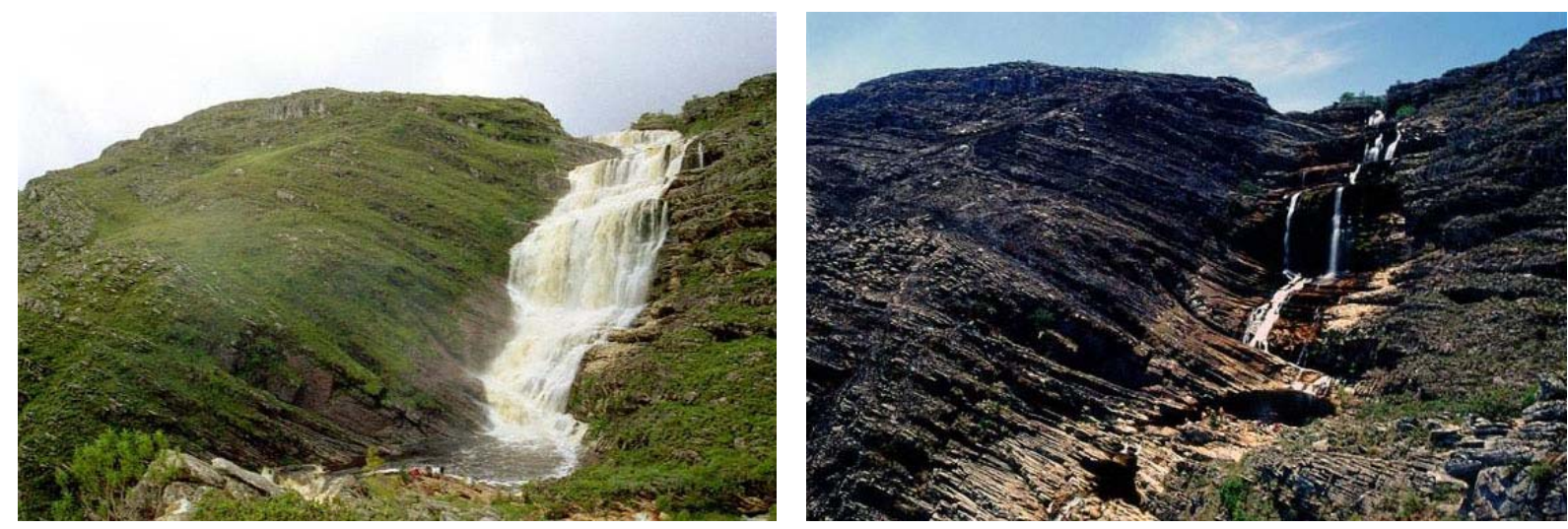

FIGURA 6:Cachoeira da Capivara. Entorno do Parque Nacional da Serra do Cipó- Serra do Cipó, MG. Antes e após queimada provocada pelo homem. Foto: Gustavo Baxter.

O processo de adaptação de paisagens e a exigência relacionada à construção de grandes estruturas de apoio turística (resorts, hotéis de luxo, estruturas de alimentação e entretenimento), geram questionamentos: o que é realmente preciso para implantar o Ecoturismo? Paisagens essencialmente modificadas são atrativas? A comunidade local sente-se em sua própria "casa", a partir das mudanças de paisagem originadas dessas construções? Parece-nos que há uma resposta negativa para cada um dessas questões.

Segundo Coriolano (2003a:124),

o Ecoturismo é uma modalidade de turismo dirigido a grupos especiais, evitando grandes concentrações e, sobretudo, integrando o turismo como atividade econômico-social ao meio ambiente natural. O ecoturista não é um turista qualquer, mas aquele turista que gosta de viagem para contato com a natureza, gosta de ver fauna e flora e de conversar com o povo visitado.

A mesma autora ainda coloca que as confusões conceituais e discussões entre os termos Ecoturismo e Turismo Ecológico podem ser inúteis, já que o Ecoturismo é, 
e deveria ser uma atividade de baixo impacto. Todos os segmentos de turismo deveriam ser ecológicos, ou seja, valorizarem as relações intrínsecas entre o ser humano e seu entorno, seja uma visita a um museu, uma igreja, uma Unidade de Conservação, ou uma área natural sem titulação ante a legislação. Deve, também, respeitar a capacidade de suporte da localidade (Figura 7).

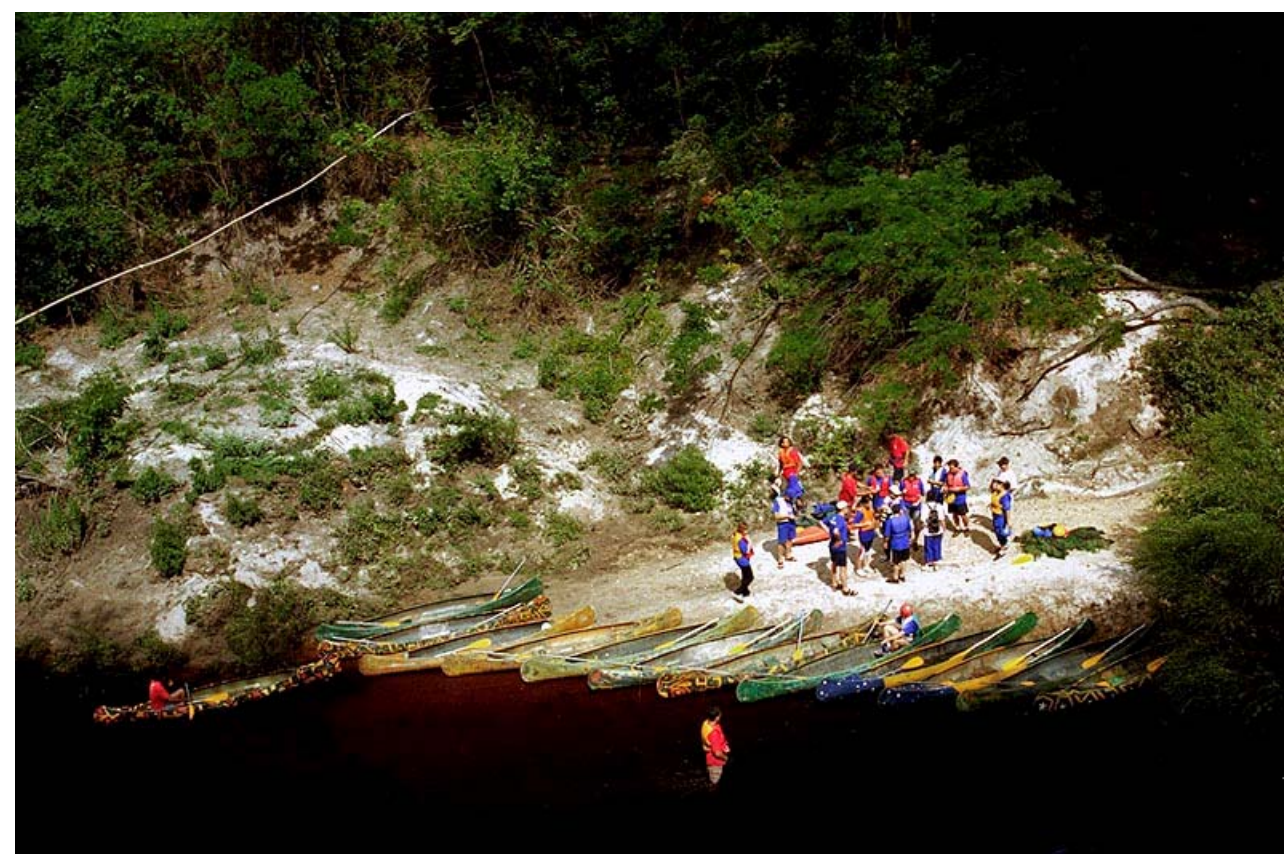

Figura 7: Prática de Canoagem Rio Cipó, atendendo os limites do recurso hídrico. APA Morro da Pedreira, Serra do Cipó,MG. "Programa Treinar". Foto: Gustavo Baxter.

A venda, a banalização e o uso equivocado de termos e práticas como Ecoturismo, Educação Ambiental, conservação e preservação, biodiversidade, desenvolvimento e turismo sustentável, como também a fuga para locais diferentes da realidade cotidiana e das pressões urbanas, tendem a motivar, a busca pelo natural. Porém, nem tudo que é realizado em ambiente natural é atividade ecoturística.

No mercado atual, práticas de natureza e aventura são comercializadas como Ecoturismo, e não o são, como já mencionado anteriormente. As mesmas fazem uso de uma montanha, uma trilha, uma Unidade de Conservação, um rio, uma formação rochosa, uma situação natural, mas de fato, só fazem uso de um cenário que é natural, não tendo a contemplação como objetivo. "No Ecoturismo deve haver, além da conservação, essa proteção o que equivale a apenas contemplar e observar a natureza". (CORIOLANO, 2003a:124)

Em observações por nós realizadas, vale ressaltar o exemplo de inúmeras agências ou receptivos turísticos locais, instalados no município de Barreirinhas-MA. $\mathrm{Na}$ sede do município encontra-se a portaria principal do Parque Nacional dos Lençóis Maranheses. Nesta localidade, as dunas e as lagoas são usadas como cenário 
de turismo de aventura e natureza. Não é legitimo as considerações que colocam aquela paisagem/cenários (por sinal atrativo de hierarquia especial diante de sua beleza e particularidades) e as práticas realizadas dentro dos enquadramentos do Ecoturismo. Em visita ao Parque, observamos um cenário caótico de empreendimentos, carros adaptados, trânsito carregado no sentido do atrativo, poucas estratégias de manejo e conservação e valorização mínima da comunidade local.

Para visitar o Parque há a exigência do acompanhamento por um condutor, visando garantir a segurança do turista durante a visitação e a conservação do local. Segundo guia local (em visita a localidade em 2007, para estudo de caso), existem operadoras turísticas no país que cobram $\mathrm{R} \$ 350,00$ pelo complemento de seu pacote turístico para conhecer os "lençóis", mas a remuneração do nativo condutor era de R\$ 12,00 a diária. Em nova visita ao município (2009), outros guias locais afirmaram que as diárias, após a formação da cooperativa local de serviços turísticos, aumentaram para $R \$ 20,00$ a $R \$ 30,00$. Por mais que resultados positivos possam ser constatados, os valores da diária no mercado atual vão de $R \$ 50,00$ a $R \$ 100,00$ em outros destinos.

Claro que há que se considerar uma série de fatores, como qualidade do produto, custo de vida local, outras oportunidades de ganho financeiro associadas, valor de mercado do destino etc., mas em nossa opinião, tal prestador de serviço jamais poderá vir a conservar seus recursos naturais, paisagísticos e de biodiversidade, acreditando que o Ecoturismo é sempre realizado por grandes fluxos de visitantes, impactos na biodiversidade e baixa remuneração da comunidade envolvida.

Apesar de não comungar com as definições de CORIOLANO (2003a) que diferencia o Ecoturismo do Turismo Ecológico, Seabra e Neu (2003:141) afirmam que,

(...) como são estranhos aos processos de modernização da paisagem natural com fins de uso turístico, as comunidades locais de base familiar abandonam seus postos de trabalho e passam a constituir uma mão de obra periférica ao turismo traduzida quase que literalmente na mendicância e na marginalidade.

Os processos de exclusão podem vir a impactar a conservação ambiental, através do incentivo não oficial ao desmatamento ilegal, queimadas, comercializações de espécies nativas, entre outras. Em observações realizadas no Parque Estadual de Ibitipoca, situada no município de Conceição de Ibitipoca, MG, também observamos atrativos, como cavernas e as cachoeiras altas, serem fechados devido a sua destruição. O desrespeito à capacidade compromete seriamente a biodiversidade local.

Ainda cabe ser ressaltado que muitas Unidades de Conservação não tem seus Planos de Manejo elaborados e, consequentemente, não possuem ferramentas que regulamentem se uso.

A discussão sobre a complementação, a multi e a transdisciplinaridade exigidas pela atividade turística é urgente e de fundamental importância para a implantação de 
programas de gestão e desenvolvimento. E, no entanto, Oliveira et al. (2008), apontam a implantação da atividade do Ecoturismo na vegetação manguezal como atividade "salvadora".

A somatória de uma gestão turística fundamentada na convergência dos interesses da atividade com preservação e conservação das dimensões ecológicas, econômica, social, cultural e religiosa, promoverá uma conscientização da população no tocante a conservação do ecossistema, evitando a superexploração e poluição do mesmo (OLIVEIRA, et al., 2005:53).

No entanto, os autores correm o risco de serem parciais se, além de afirmar que a "Educação Ambiental, uma das diretrizes básicas para a preservação dos ecossistemas para gerações futuras, está diretamente ligada ao turismo pedagógico e ecológico" (p.63), não considerarem os problemas reais, correlacionados ao uso, particularidades da biodiversidade, e exclusão social das comunidades do normalmente observados em atividades de Ecoturismo em área de manguezais.

Não é o simples fato de se autodenominar como "turismo ecológico" ou "pedagógico" que uma atividade deixará de ser impactante. Tudo dependerá do formato de sua realização, da prática e dos condicionantes que o sustentam.

Os bons exemplos de gestão e comercialização do Ecoturismo em outros países poderiam orientar as práticas no Brasil, para que se possa substituir atividades potencialmente impactantes aos ambientes. Na Chapada Diamantina/BA, por exemplo, observamos a prática de turismo na natureza com baixos impactos em a substituição da atividade de garimpo (Figura 8).

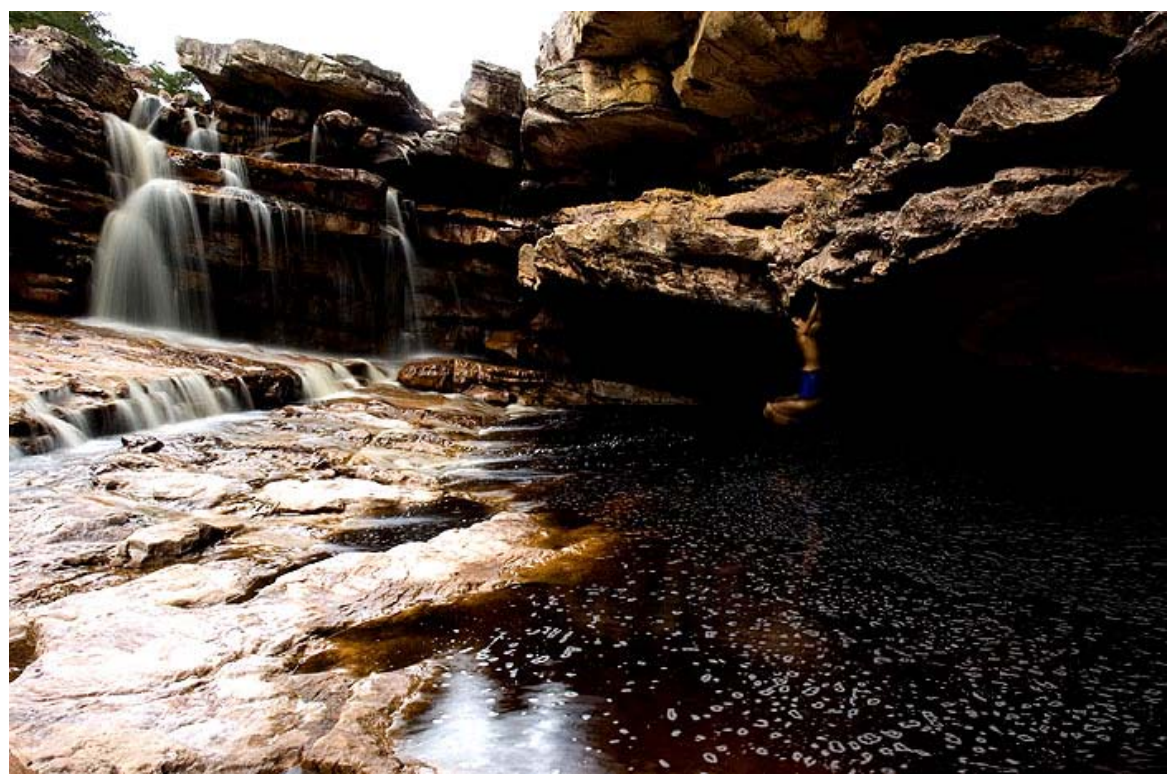

Figura 8: Prática de Escalada Boulder. Parque Nacional da Chapada Diamantina, Igatu, BA. Foto: Gustavo Baxter. 
Foi em Igatu-BA que escaladores da pratica Bolder repensaram a pratica do turismo em substituição ao garimpo, em julho de 2008, ao proporem a realização das filmagens de "A Gruna", documentário que propõe o reconhecimento a região como um local de garimpo já em decadência , mas com destacado potencial para a pratica desse tipo de escalada, a partir dos resíduos paisagísticos da atividade de extração, em áreas do município e do Parque Nacional da Chapada Diamantina.

Infelizmente, ao contrário,

em Canoa Quebrada, os moradores constataram que o turismo trouxe vantagens como renda e poucos empregos seguros; mas por outro lado, as pousadas e restaurantes e lojas eram de pessoas de fora, a criminalidade aumentou e o consumo das drogas e da prostituição eram um problema sério... em Parajurú, os moradores não viram benefício positivo nenhum do turismo... na Prainha do Canto Verde a pesquisa revelou que os moradores estavam conscientes que o turismo ia chegar, mas também sabiam que queriam um turismo diferente (SCHARER, 2003:333).

Este trabalho, que tem como objetivo contextualizar e aproximar teorias e práticas através de observações em localidades turísticas, detectou, no Brasil, bons exemplos, que conseguem respeitar particularidades locais, como os municípios de BonitoMT, Fernando de Noronha-PE, e Prainha do Canto Verde/Beberibe-CE, que, por mais que apresentem dificuldades, mostraram-nos que estão conseguindo usar, monitorar e conservar a biodiversidade, mesmo com o quadro de visitação no qual se encontram atualmente. Essas localidades ainda conseguem atrair adeptos para a prática do uso sustentável e da conservação.

O Parque Nacional do Caparaó, que tem uma de suas portarias em território capixaba (município de Dores do Rio Preto), a implantação de ações como a Brigada de Incêndio Comunitária, formação de "guarda- parques" e programas de hospedagem como o "Break and Breakfest - Cama e Café" (hospedagem familiar na casa dos moradores locais), vêm subsidiando e agregando valor e profissionalismo de forma integrada, a uma das atividades de observação de natureza e Ecoturismo mais antigas do Brasil - a escalada ao Pico da Bandeira.

Alguns outros projetos no Brasil também devem ainda ser comentados, como o "Projeto Conservação Local e o Turismo - A Educação Ambiental voltada para o fomento do Ecoturismo no Município de Rio Preto, Minas Gerais" (RODRIGUES, 2005), que visa sensibilizar, discutir e destacar a Bacia Hidrográfica do Rio Preto como motivo para a prática do Ecoturismo. O Rio Preto tem sua nascente dentro do Parque Nacional do Itatiaia-RJ, portanto, com água de qualidade, grande volume de bacias hidrográficas elementares, beleza cênica e possibilidade de implantação de turismo de pequenos impactos em conjunto com a população local. A fase das discussões e sensibilização a respeito do que é o Ecoturismo, demonstrou bons resultados relacionados à percepção ambiental dos participantes.

Outro exemplo de projeto e ação é o denominado de "O mico-leão-dourado (Leontopitecus rosalia) - um raro produto para o Ecoturismo e a conservação da mata 
Rodrigues, G. B.; Amarante-Junior, O. P.

atlântica". O mesmo também realiza dinâmicas de observação da espécie, atividade de interpretação e percepção ambiental. Tais atividades fomentam a sensibilização para a conservação e preservação, para esta importante espécie componente da Biodiversidade (NUNES, et al., 2007)

\section{Considerações Finais}

Apesar de incipientes e/ou contraditórios em alguns aspectos, tais exemplos ilustram ações que podem ser classificadas como atividade de Ecoturismo, porque envolvem tanto os participantes locais da comunidade, como os próprios turistas e o espaço físico-biológico.

Diante de aspectos conceituais, comerciais, e de cenário e mercado, a implantação do Ecoturismo contemplativo (com pequenos grupos, envolvimento de atores locais, conservação e valorização da biodiversidade) pode, além de uma medida de incremento do PIB brasileiro, promover desenvolvimento para as gerações futuras, com possibilidades de mobilização social e visitação que promova o prazer de se estar em um lugar natural conservado.

Por fim, achamos importante fazer algumas ressalvas. As ações pontuais do Ecoturismo, apesar de, a cada dia, exigirem mais participação comunitária para fiscalização, gestão e uso de recursos em territórios específicos, ainda não geram benefícios efetivos para as comunidades locais. Scharer (2003:333), por exemplo, observou que no caso da prainha do Canto Verde, "os veranistas fizeram pouco para alimentar a economia do lugar, já que traziam tudo de Fortaleza e consumiam quase nada no local."

Essa situação redunda em pouca participação efetiva das populações locais com relação à conservação de seus atrativos, a não formação de arranjos produtivos locais, e ainda causa a exaustão de todo um conjunto de paisagem, sem promoção do desenvolvimento humano. Há uma reprodução de modelos de uso que fazem da biodiversidade um mero produto lucrativo.

Com o esgotamento dos componentes da paisagem, sempre surgem movimentos de deslocamentos em busca de outros paraísos Ecoturísticos, podendo ocasionar novos impactos negativos. Para que o impacto das visitações do Ecoturismo e do turismo de aventura possam ser mais positivos do que negativos, é preciso repensar como a mobilização comunitária possa acontecer, qual a percepção dessa comunidade com relação à paisagem do qual faz parte, e implantar ações de sensibilização que sejam condizentes com a realidade daquela população. Sobretudo, é necessário que consigamos difundir, com linguagens mais acessíveis, os conhecimentos acadêmicos produzidos para o segmento.

Repensar o Ecoturismo, atualmente, é implantar novos formatos de gestão e participação, exigindo discussões embasadas sobre o que é sustentabilidade e particularidade física, biológica, social e econômica de cada lugar. Portanto, o empréstimo de modelos, no caso do Ecoturismo, não pode ser uma prática recorrente. A lógica a ser seguida, na nossa opinião, é a que considera cada local com seu jeito e seu saber 
fazer, mas busca diretrizes básicas para que haja adequação de teorias e modelos com as realidades em questão, para a conservação de rochas, cachoeiras, biomas, e de todo um cenário natural, para a prática da contemplação e de uso esportivo (Figura 9).

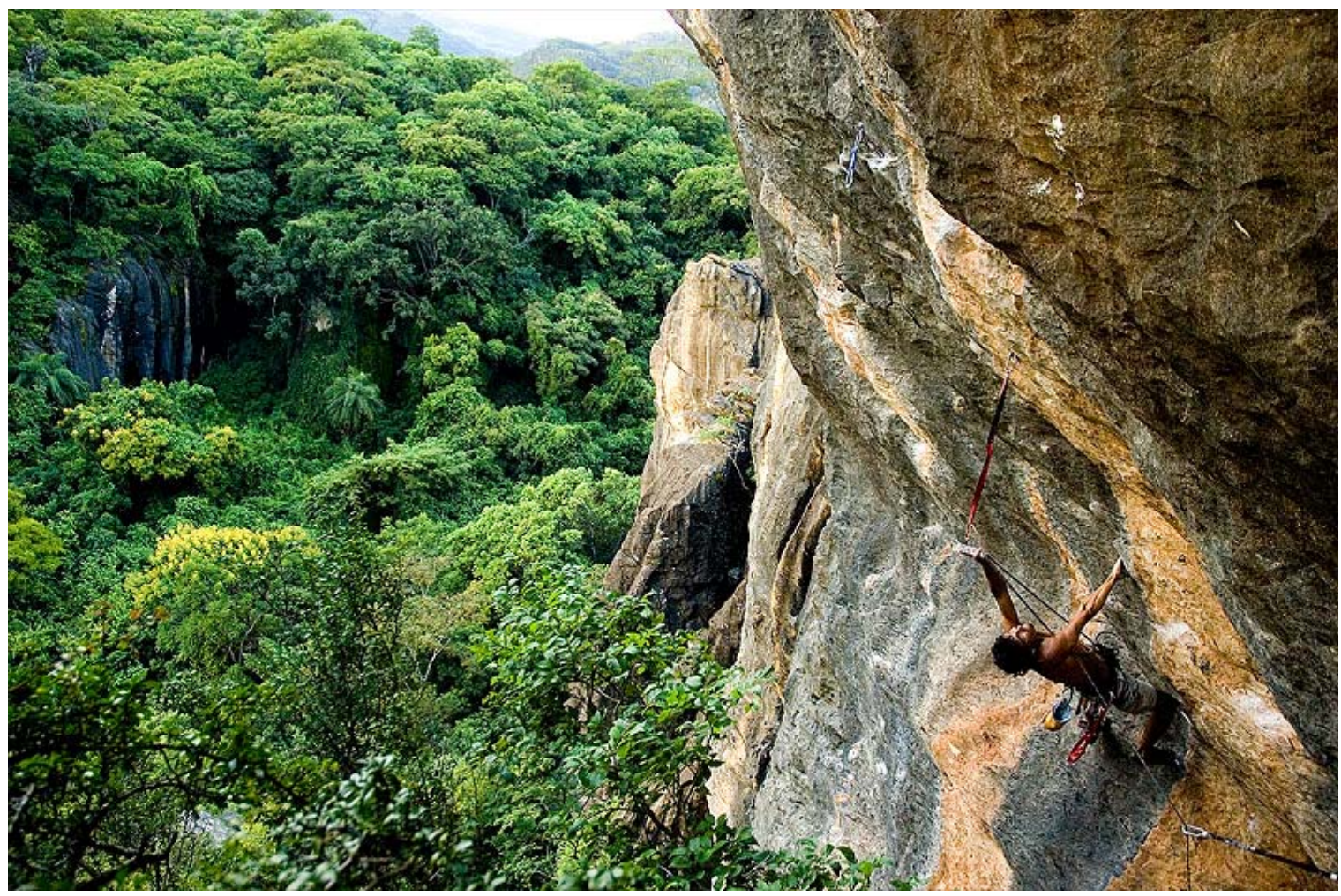

Figura 9: Prática de Escalada Esportiva aliada com a conservação dos atrativos da APA Morro da Pedreira, Serra do Cipó, MG. Foto: Gustavo Baxter.

\section{Referências Bibliográficas}

BROWN, J.H.; LOMOLINO, M.V. Biogeografia. Ribeirão Preto: FUNPEC Editora, $2^{\mathrm{a}}$,Ed., 2006.

CORIOLANO, L.N.M.T. Os limites do desenvolvimento e do turismo. In: CORIOLANO, L.N.M.T. (org). O Turismo de Inclusão e o desenvolvimento local. Fortaleza: Ed. Premius, 2003a.

CORIOLANO, L. N. M. T. O Ecoturismo e os hóspedes da natureza. In: CORIOLANO, L. N. M. T. ; LIMA, L. C. (orgs.). Turismo comunitário e responsabilidade socioambiental. Fortaleza: EDUECE, 2003b. 
Rodrigues, G. B.; Amarante-Junior, O. P.

CORIOLANO, L. N. M. T.; LIMA, A.C.G. A contribuição do turismo no desenvolvimento local. Curso a distância em Gestão da Cadeia Produtiva do Turismo. Universidade Aberta do Nordeste. 2008.

MORAIS, E.O.; SARAIVA-FILHO, R.A. Desvendando os caminhos do turismo de aventura. Curso a distância em Gestão da Cadeia Produtiva do Turismo. Universidade Aberta do Nordeste. 2008.

NUNES, A.L.; FERNANDES, R.V.; BOUCINHA, V.; TOLEDO, C..O; MARTINS, A. O mico-leão-dourado (Leontopitecus rosalia): um raro produto para o Ecoturismo e a

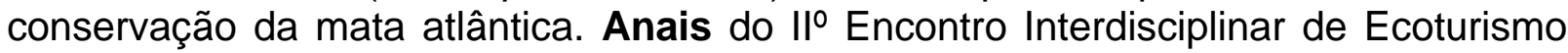
em Unidades de Conservação e VIº Congresso Nacional de Ecoturismo, 2007.

OLIVEIRA, L.A.K.; FREITAS, R.R.; BARROSO, G.F. Manguezais: Turismo e Sustentabilidade. Caderno Virtual de Turismo, v.5 (3), 2005, pp.52-56.

REJOWSKI, M. (org.) Turismo no Percurso do Tempo. São Paulo: Editora Aleph, 2002.

RODRIGUES, G.B. A Educação Ambiental voltada para o fomento do Ecoturismo no Município de Rio Preto - Minas Gerais. Monografia: Curso de Especialização em Educação ambiental para Bacias Hidrográficas: perspectivas e desafios para o século XXI . São Carlos: USP, 2005

SANCHO, A. Introdução ao Turismo: Organização Mundial de Turismo, OMT. São Paulo: Roca,2001.

SEABRA, G.F.; NEU, C. A face social do Ecoturismo no Parque Nacional da Chapada Diamantina. In: CORIOLANO, L. N. M. T. ; LIMA, L. C. (orgs.). Turismo comunitário e responsabilidade socioambiental. Fortaleza: EDUCE, 2003.

SHARER, R. O Turismo sustentável na Prainha do Canto Verde. In: CORIOLANO, L.N.M.T. (org). O Turismo de Inclusão e o desenvolvimento local. Fortaleza: Ed. Premius, 2003.

URRY, J. O olhar do turista. Lazer e viagens nas sociedades contemporâneas. São Paulo:Studio Nobel-SESC, 1996.

WESTERN, D. Como definir o Ecoturismo. In: LINDBERG, K.; HAWKINS, D.E. (org.). Ecoturismo: um guia para planejamento e gestão. São Paulo: SENAC, 2002. 
NOTA

${ }^{1} \mathrm{O}$ trabalho intitulado "Ecoturismo, conservação ambiental, marketing e realidade: conceitos e práticas", foi elaborado e solicitado como trabalho final da disciplina de Biologia da Conservação, do Programa de Pós Graduação em Biodiversidade e Conservação da UFMA. O mesmo apresentou como método de elaboração uma revisão bibliográfica pautado sob a análise de alguns artigos científicos. Ainda considerou importantes bibliografias para o embasamento e a discussão do tema, como também vivências e exemplos relacionados a localidades que tem a atividade do turismo em fase de implantação, ou já consolidada. O Projeto de pesquisa de mestrado de tal autora é intitulado "A conservação da biodiversidade e da paisagem em Território Quilombola , Bacabal MA" e conta com financiamento da FAPEMA - Fundo de Amparo "Fundação de Amparo à Pesquisa e ao Desenvolvimento Cientifico e Tecnológico do Maranhão", à UFMA, IF-MA. Os agradecimentos vão para o fotógrafo Gustavo Baxter, por seus registros belíssimos e importantes para o acervo imagético do Ecoturismo e do Turismo de aventura e natureza no Brasil. Como também pela parceria e amizade durante nossa trajetória.

Gabriela Barros Rodrigues : Universidade Federal do Maranhão - UFMA

Email: gabi_andar@hotmail.com

Link para o currículo Lattes: http://lattes.cnpq.br/7225033654870305

Ozelito Possidônio de Amarante Junior: Instituto Federal de Educação, Ciência e Tecnologia do Maranhão - IFMA e Universidade Federal do Maranhão - UFMA

Email: ozelito@hotmail.com

Link para o currículo Lattes: http://lattes.cnpq.br/7857430001310706

Data de submissão: 27 de fevereiro de 2009

Data do aceite: 15 de maio de 2009 